\title{
PENGARUH KONSENTRASI KATALIS DAN WAKTU REAKSI PADA PEMBUATAN EPOKSI MINYAK GORENG BEKAS
}

\section{(EFFECT OF CATALYST CONCENTRATION AND REACTION TIME TO EPOXY PRODUCTION FROM WASTE COOKING OIL)}

\author{
Yenni Listiana*, Hilde Rosa Tampubolon, Mersi Suriani Sinaga \\ Departemen Teknik Kimia, Fakultas Teknik, Universitas Sumatera Utara, Jl. Almamater Kampus USU \\ Medan 20155, Indonesia \\ *Email : Yennilistiana96@gmail.com
}

\begin{abstract}
Abstrak
Senyawa epoksi adalah senyawa yang dihasilkan dari reaksi epoksidasi minyak nabati atau minyak alam yang memiliki ikatan tidak jenuh. Senyawa epoksi dapat diaplikasikan sebagai stabilisator, plasticizers pada polivinil klorida (PVC) serta dapat digunakan sebagai antioksidan pada pengolahan karet alam, sebagai surfaktan, agen anti korosif aditif pada minyak pelumas dan bahan baku pestisida. Tujuan dari penelitian ini adalah pemanfaatan limbah minyak goreng bekas sebagai bahan baku untuk membuat senyawa epoksi. Penelitian ini dilakukan dengan mereaksikan minyak goreng bekas dengan heksana sebagai pelarut, asam sulfat sebagai katalis, asam asetat glasial dan $\mathrm{H}_{2} \mathrm{O}_{2}$. Konsentrasi katalis yang digunakan adalah $1,5 \%, 2,1 \%, 2,5 \%, 3,1 \%$ dan 3,5\% dan waktu reaksi epoksidasi adalah 60,120 , 180, 240 dan 300 menit. Hasil penelitian menunjukkan bahwa waktu reaksi optimum adalah 300 menit dengan konsentrasi katalis 1,5\% diperoleh bilangan iod sebesar $0,96 \mathrm{~g} \mathrm{I}_{2} / 100 \mathrm{~g}$ minyak goreng bekas dengan kandungan oksigen oksiren sebesar 1,872 dan konversi oksigen oksiren sebesar 62,259\%.
\end{abstract}

Kata kunci : Epoksidasi, Epoksi, Oksigen Oksiren

\begin{abstract}
Epoxy is produced from an epoxidation of vegetable oil or natural oil with an unsaturated bond. Epoxy can be applied as a stabilizer, plasticizers in polyvinyl chloride (PVC) and can be used as an antioxidant in natural rubber processing, as a surfactant, anti-corrosive additive agent in lubricants and pesticide raw materials. The purpose of this research was to evaluate epoxy production from waste cooking oil. In this research, waste cooking oil was reacted with hexane as solvent, sulfuric acid as catalyst, glacial acetic acid and hydrogen peroxide. The catalyst concentration was varied from $1.5 \%$, $2.1 \%, 2.5 \%, 3.1 \%$ and $3.5 \%$ and the epoxidation time was varied from 60, 120, 180, 240 and $300 \mathrm{~min}$. The results showed that highest epoxy yield was achieved at reaction time of $300 \mathrm{~min}$ and $1.5 \%$ catalyst. At that condition, the iod number was 0,96 g I $/ 100 \mathrm{~g}$ WCO, oxirane oxygen content was 1.872 and oxirane oxygen conversion was $62.259 \%$.
\end{abstract}

Keywords: Epoxidation, Epoxy, Oxirane Oxygen

\section{Pendahuluan}

Banyaknya limbah yang dihasilkan oleh industri dan rumah tangga menyebabkan masalah bagi lingkungan salah satu contoh yaitu minyak goreng bekas. Meningkatnya jumlah minyak goreng bekas dapat menimbulkan permasalahan akibat kurangnya pemanfaatan. Salah satu alternatif yang dapat digunakan yaitu memanfaatkan minyak goreng bekas sebagai bahan baku pembuatan senyawa epoksi.

Senyawa epoksi merupakan hasil yang diperoleh dari proses epoksidasi [6]. Senyawa epoksi dapat diaplikasikan sebagai stabilisator, plasticizers pada polivinil klorida (PVC) untuk meningkatkan fleksibilitas dan elaksitas PVC [3], serta dapat digunakan sebagai antioksidan pada pengolahan karet alam, sebagai surfaktan, agen anti korosif aditif pada minyak pelumas dan bahan baku pestisida. Reaktivitas cincin oksiran yang tinggi menyebabkan epoksi juga dapat digunakan sebagai bahan baku untuk beberapa bahan kimia seperti alkohol, glikol, alkanolamina, senyawa karbonil, senyawa olefin dan senyawa polimer seperti poliester, poliuretan dan epoksi resin [16].

Senyawa epoksi dapat disintesa dari minyak nabati seperti minyak kedelai, minyak biji bunga matahari, minyak jarak dan minyak sawit [12]. Minyak nabati merupakan minyak yang mempunyai sifat antifriksi yang baik, misalnya sifat pelumasan yang baik, volatilitas rendah, indeks viskositas tinggi, kelarutan terhadap aditif pelumas tinggi dan kemudahannya saling larut dengan fluida lain [9].

Bahan baku senyawa epoksi yang berasal dari minyak nabati dapat berupa minyak nabati mentah ataupun minyak nabati yang sudah mengalami penggolahan lebih lanjut [4]. Salah satu jenis minyak nabati yang dapat digunakan sebagai bahan baku pembuatan senyawa epoksi 
adalah minyak kelapa sawit [6]. Salah satu produk yang dihasilkan dari minyak kelapa sawit yaitu minyak goreng bekas. Minyak goreng bekas mengandung asam oleat $22,64 \%$, asam linoleat $52,68 \%$, dan asam linolenat $2,60 \%$ yang merupakan asam lemak tak jenuh dan asam palmitat $17,34 \%$, asam stearat $4,21 \%$ yang merupakan asam lemak jenuh [14].

Pada tahun 2007 jumlah minyak goreng bekas yang dihasilkan yaitu sekitar 3.886.989,6290 ton per tahun [13]. Tingginya jumlah minyak goreng bekas yang tersedia sebagai limbah menjadi tantangan terbesar karena masalah pembuangan yang dapat mengganggu kesetimbangan lingkungan seperti terkontaminasinya sumber daya air tanah. Meskipun beberapa limbah minyak goreng ini dapat digunakan sebagai bahan baku pembuatan sabun [16].

Penelitian ini bertujuan untuk mengetahui pengaruh waktu reaksi dan katalis $\mathrm{H}_{2} \mathrm{SO}_{4}$ pada pembuatan senyawa epoksi dengan bahan baku minyak goreng bekas dan untuk meningkatkan nilai tambah dari minyak goreng bekas.

\section{Teori}

Senyawa epoksi merupakan senyawa yang dihasilkan dari reaksi epoksidasi minyak nabati atau minyak alam yang memiliki ikatan tidak jenuh. Penggunaan minyak alam sebagai bahan baku senyawa epoksi sudah jarang dilakukan dengan alasan keterbatasan sumber bahan baku minyak alam. Minyak nabati merupakan bahan baku yang saat ini banyak digunakan untuk sintesa senyawa epoksi [4]. Reaksi epoksidasi merupakan reaksi pembentukan cincin epoksida yang dapat disintesis dengan mereaksikan alkena dan oksigen aktif. Pada umumnya, epoksidasi minyak menggunakan $\mathrm{H}_{2} \mathrm{O}_{2}$ sebagai oksidan. Sifat $\mathrm{H}_{2} \mathrm{O}_{2}$ sebagai oksidator tidak cukup kuat sehingga harus diubah menjadi pereaksi yang lebih aktif (asam peroksi) [1]. Epoksidasi merupakan eter siklik dengan cincin tiga anggota. Reaksi epoksidasi yaitu suatu reaksi oksidasi ikatan rangkap dalam minyak oleh oksigen aktif yang membentuk senyawa epoksida. Metode yang sering digunakan untuk mensintesa epoksida adalah reaksi dari suatu alkena dengan suatu asam peroksi organik, yaitu suatu proses yang disebut epoksidasi [16].

Persamaan reaksi dari proses epoksidasi adalah sebagai berikut:

$$
-\stackrel{\mathrm{C}}{\mathrm{C}}=\stackrel{\mathrm{I}}{\mathrm{C}}-+\mathrm{RCO}_{3} \mathrm{H} \longrightarrow \mathrm{C}_{\mathrm{O}}^{-} \stackrel{\mathrm{I}}{-}^{-}+\mathrm{RCO}_{2} \mathrm{H}
$$

Gambar 1. Reaksi dari Proses Epoksidasi Hidrokarbon
Peroksi dapat dibentuk melalui interaksi antara asam karboksilat dengan hidrogen peroksida, biasanya dengan adanya asam sulfat, asam metan sulfonat atau asam polistiren sulfonat (resin penukar ion positif) [6]. Minyak nabati yang baik digunakan dalam pembuatan senyawa epoksi, adalah minyak yang mengandung asam lemak tidak jenuh relatif tinggi, misalnya minyak kedelai [4].

Dalam proses pembuatan senyawa epoksi dari olefin, asam lemak tidak jenuh dan ester tidak jenuh, yang direaksikan dengan asam peroksi alifatik. Asam peroksi asetat bebas air diperoleh dari reaksi antara asam asetat anhidrat dan hidrogen peroksida [5].

Senyawa epoksi dengan nilai oksiren yang tinggi dan kadar bilangan iod yang rendah menunjukkan mutu yang baik [11]. Jenis katalis yang dapat digunakan pada reaksi epoksidasi seperti asam sulfat pekat dan resin penukar ion. Produksi optimal senyawa epoksi diperoleh dengan menggunakan pelarut inert seperti benzen dan heksan. Katalis asam sulfat atau resin ambarlite dan lama reaksi sekitar 8-14 jam. Reaksi ini dapat dipersingkat dengan menggunakan hidrogen peroksida yang berlebih [1].

\section{Metodologi Penelitian \\ Bahan dan Peralatan}

Bahan baku yang digunakan dalam penelitian ini adalah minyak goreng bekas dari usaha Roti Ketawa Pelangi, Pematangsiantar, heksana pro analis $\left(\mathrm{C}_{6} \mathrm{H}_{14} 40 \%\right)$, asam asetat glasial pro analis $\left(\mathrm{CH}_{3} \mathrm{COOH} 100 \%\right)$, hidrogen peroksida $\left(\mathrm{H}_{2} \mathrm{O}_{2} 30 \%\right)$, asam sulfat $\left(\mathrm{H}_{2} \mathrm{SO}_{4} 96 \%\right)$ sebagai katalis, kalium iodine untuk analisis (KI), karbon tetraklorin untuk analisis, reagen wijs merek KGaA, Jerman, Natrium Thiosulfat $\left(\mathrm{Na}_{2} \mathrm{~S}_{2} \mathrm{O}_{3}\right)$, Hidrogen bromide untuk analisi $(\mathrm{HBr})$. Peralatan yang digunakan dalam penelitiana ini adalah labu leher tiga $500 \mathrm{ml}$ sebagai tempat berlangsungnya reaksi, yang dilengkapi dengan termometer, hot plate yang dilengkapi magnetis stirrer digunakan sebagai media pemanas, refluks, corong pemisah, rotary evaporator dan timbangan digital. Penelitian dilakukan dengan variasi persen katalis dan variasi waktu dengan kecepatan putaran $500 \mathrm{rpm}$. Bahan baku minyak goreng bekas akan dilakukan analisa dengan alat Gas Chromatography (GC) type Shimadzu QP 2010 Brands dan hasil senyawa epoksi akan dilakukan analisis Fourier Transform Infra Red (FTIR) type Alpa FTIR Spectrometers.

\section{Prosedur Kerja}

Reaksi epoksidasi dimulai dengan mencampur minyak goreng bekas dengan 
heksana, asam asetat glacial dan asam sulfat sebagai katalis. kemudian dipanaskan. Setelah temperatur campuran mencapai $50^{\circ} \mathrm{C}$, kemudian ditambahkan hidrogen peroksida 30 persen perlahan-lahan temperatur dipertahankan $60{ }^{\circ} \mathrm{C}$ selama penambahan hidrogen peroksida [10]. Setelah selesai penambahan hidrogen peroksida. Kemudian campuran dipanaskan sesuai dengan temperatur dan waktu yang ditentukan berdasarkan perlakuan percobaan. Kemudian campuran dicuci dan dievaporator untuk menghilangkan heksana. Analisis yang dilakukan yaitu Analisis bilangan iod menggunakan metode wijs (SNI-01-3555-1998) dan analisis bilangan oksigen oksiren (AOCS Official Methods Cd 957(1989)).

\section{Hasil}

Bahan baku minyak goreng bekas ini dianalisis menggunakan GC untuk mengetahui komposisi asam-asam lemak yang terkandung didalamnya. Komposisi asam lemak minyak goreng bekas tersebut dapat dilihat pada tabel 1 .

Tabel 1. Komposisi Asam Lemak dari Minyak Goreng Bekas

\begin{tabular}{|c|c|c|}
\hline $\begin{array}{c}\text { Retention } \\
\text { Time } \\
\text { (Menit) }\end{array}$ & $\begin{array}{l}\text { Komponen } \\
\text { Penyusun }\end{array}$ & $\begin{array}{c}\text { Komposisi } \\
\%(\mathbf{b} / \mathbf{b})\end{array}$ \\
\hline 10,998 & $\begin{array}{ll}\text { Asam } & \text { laurat } \\
\left(\mathrm{C}_{12: 0}\right) & \end{array}$ & 0,57 \\
\hline 13,543 & $\begin{array}{l}\text { Asam miristat } \\
\left(\mathrm{C}_{14: 0}\right)\end{array}$ & 1,70 \\
\hline 16,000 & $\begin{array}{l}\text { Asam palmitat } \\
\left(\mathrm{C}_{16: 0}\right)\end{array}$ & 32,05 \\
\hline 18,200 & $\begin{array}{l}\text { Asam stearat } \\
\left(\mathrm{C}_{18: 0}\right)\end{array}$ & 8,04 \\
\hline 20,214 & $\begin{array}{l}\text { Asam arakidat } \\
\left(\mathrm{C}_{20: 0}\right)\end{array}$ & 0,86 \\
\hline 16,270 & $\begin{array}{l}\text { Asam palmitoleat } \\
\left(\mathrm{C}_{16: 1}\right)\end{array}$ & 0,37 \\
\hline 18,481 & Asam oleat $\left(\mathrm{C}_{18: 1}\right)$ & 41,20 \\
\hline 18,959 & $\begin{array}{l}\text { Asam linoleat } \\
\left(\mathrm{C}_{18: 2}\right)\end{array}$ & 14,49 \\
\hline 19,580 & $\begin{array}{l}\text { Asam linolenat } \\
\left(C_{18: 3}\right)\end{array}$ & 0,41 \\
\hline 20,459 & $\begin{array}{l}\text { Asam eikosenoat } \\
\left(\mathrm{C}_{20: 1}\right)\end{array}$ & 0,31 \\
\hline
\end{tabular}

Pengaruh Variasi Waktu Reaksi dan Konsentrasi Katalis terhadap Bilangan Iodium

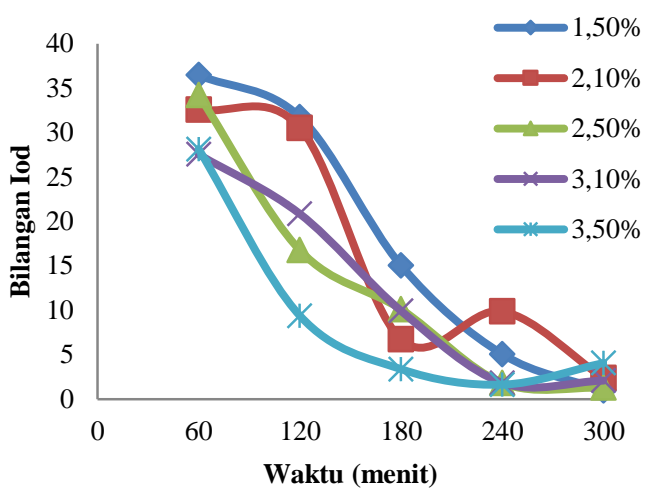

Gambar 2. Hubungan Waktu Reaksi dan Konsentrasi Katalis terhadap Bilangan Iodium

Pada gambar 2 dapat dilihat bahwa semakin lama waktu reaksi maka bilangan iodium yang diperoleh cenderung menurun. Seperti yang ditunjukkan pada gambar 2 pada konsentrasi katalis $1,5 \%$ dengan waktu reaksi 60 menit diperoleh bilangan iodium sebesar 36,48 dan mengalami penurunan pada waktu reaksi 300 menit menjadi $0,96 \mathrm{~g} \mathrm{I}_{2} / 100 \mathrm{~g}$.

Hal ini disebabkan karena pada reaksi epoksidasi minyak goreng bekas terjadi pemutusan ikatan rangkap oleh asam peroksi untuk membentuk gugus oksiran. Dengan demikian selama reaksi epoksidasi berlangsung akan terjadi penurunan bilangan iod. Besar kecilnya bilangan iodium minyak atau lemak, menunjukkan banyaknya ikatan rangkap (ikatan tidak jenuh yang terkandung dalam minyak atau lemak tersebut) [7].

Pengaruh Variasi Waktu Reaksi dan Konsentrasi Katalis terhadap Bilangan Oksigen Oksiren

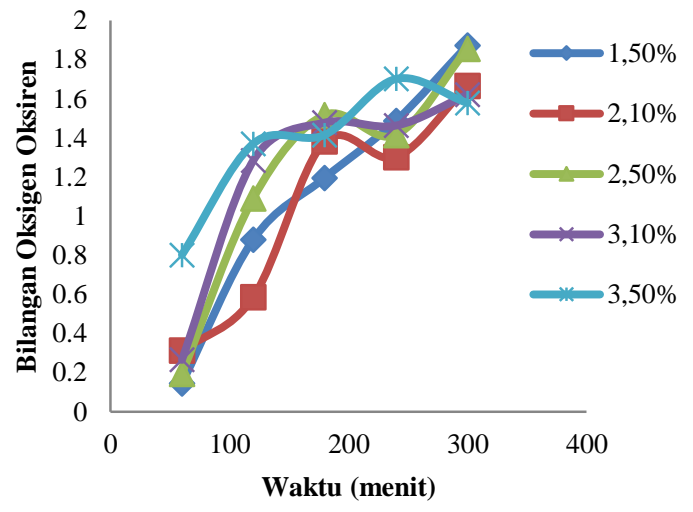

Gambar 3. Hubungan Waktu Reaksi dan Konsentrasi Katalis terhadap Bilangan Oksigen Oksiren

Pada gambar 3 dapat dilihat bahwa semakin lama waktu reaksi maka bilangan oksigen oksiren yang diperoleh cenderung semakin meningkat. Seperti yang ditunjukkan 
pada gambar 3 pada konsentrasi katalis 1,5\% dengan waktu reaksi 60 menit diperoleh bilangan oksigen oksiren sebesar 0,146 dan meningkat pada waktu reaksi 300 menit menjadi 1,872.

Hal ini disebabkan karena semakin lama waktu reaksi maka kesempatan molekul-molekul zat pereaksi untuk saling bertumbukan semakin besar [15]. Proses ini akan mengakibatkan konversi senyawa tidak jenuh menjadi senyawa epoksi meningkat sehingga rendemen senyawa epoksi yang diukur melalui bilangan oksigen oksiren juga akan meningkat.

\section{Pengaruh Variasi Waktu Reaksi dan Konsentrasi Katalis terhadap Konversi Oksigen Oksiren}

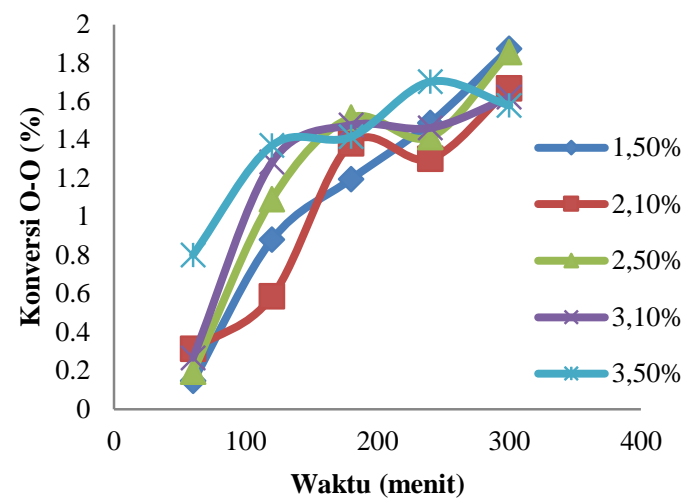

Gambar 4. Hubungan Waktu Reaksi dan Konsentrasi Katalis terhadap Konversi Oksigen Oksiren

Pada gambar 4 secara umum dapat diketahui bahwa semakin lama waktu reaksi maka bilangan konversi oksigen oksiren yang dihasilkan cenderung semakin meningkat pada kelima variasi konsentrasi katalis yang di teliti 1,5 $\%, 2,1 \%, 2,5 \%, 3,1 \%$ dan 3,5\% (v/v). Seperti yang ditunjukkan Gambar 4 pada konsentrasi katalis 1,5\% dengan waktu reaksi 60 menit diperoleh konversi sebesar 4,850\% dan meningkat pada waktu reaksi 300 menit menjadi $62,259 \%$.

Hal ini disebabkan karena kesempatan molekul-molekul pereaksi untuk saling bertumbukan semakin luas seiring dengan bertambahnya waktu reaksi [8]. Disamping itu ikatan rangkap yang terdapat dalam minyak goreng bekas semakin banyak mengalami oksidasi pembukaan ikatan rangkap oleh asam peroksi sehingga diperoleh konversi yang semakin besar. Selanjutnya mengalami penurunan bilangan oksiran, karena epoksidasi merupakan reaksi bolak balik yang berpotensi diikuti reaksi samping, sehingga epoksidasi dilakukan sesingkat mungkin [5].

\section{Hasil Analisis Fourier Transform Infra Red (FTIR) Senyawa Epoksi}

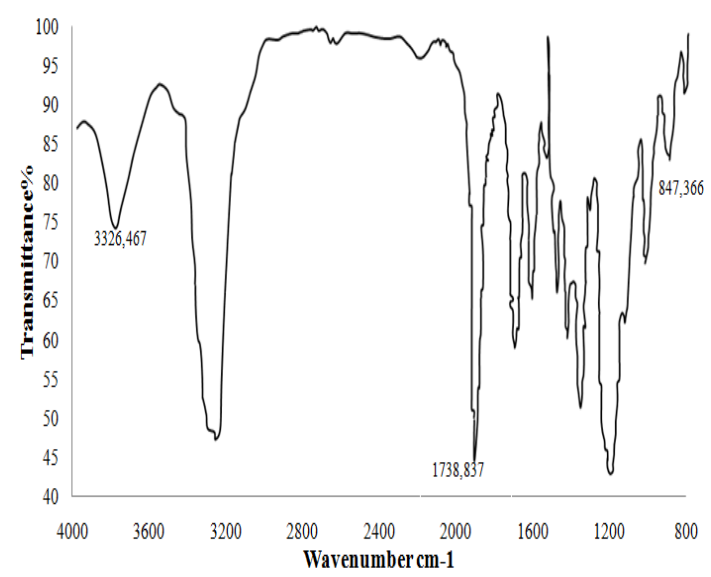

Gambar 5. Hasil Karakterisasi FTIR Senyawa Epoksi

Gambar di atas menunjukkan karakteristik FTIR yang menunjukkan beberapa serapan (peak) kunci yang dapat mengindikasikan suatu gugus sebagai ciri khusus dari sebuah senyawa.

Dari Gambar 5 dapat dilihat bahwa pada spektrum gelombang $1738,837 \mathrm{~cm}^{-1}$ terbentuk ikatan $\mathrm{C}=\mathrm{O}$ yang mengindikasikan adanya senyawa ester, yang menunjukkan epoksidasi minyak goreng bekas. Gugus $\mathrm{C}=\mathrm{O}$ ester ini berasal dari gugus karbonil yang terdapat pada senyawa epoksi. Serapan spesifik dari gugus epoksi tidak begitu tajam, karena diduga bahwa beberapa rantai epoksida tersebut mengalami pembukaan cincin hingga terbentuk gugus hidroksil, hal ini didukung oleh adanya spektrum gelombang $3326,467 \mathrm{~cm}^{-1}$ yang mengindikasikan keberadaan gugus $\mathrm{O}-\mathrm{H}$ alkohol bengkok simetris. Sedangkan pada spektrum gelombang $847,366 \mathrm{~cm}^{-1}$ terbentuk ikatan C-O-C rentang simetris kuat yang mengindikasikan adanya gugus oksiran yang terdapat pada senyawa epoksi [2].

\section{Korelasi Antara Bilangan Oksigen Oksiren dan Bilangan Iodium}

Bilangan iodium menunjukkan banyaknya ikatan rangkap (tak jenuh) dalam suatu minyak atau lemak. Bilangan iodium juga sebagai indikator tingkat epoksidasi dimana bilangan iodium akan mengalami penurunan seiring dengan semakin tingginya tingkat epoksidasi. Penurunan bilangan iodium disebabkan karena degradasi senyawa ikatan rangkap oleh senyawa asam peroksi. Sedangkan bilangan oksigen oksiren merupakan parameter yang khas untuk menentukan mutu produk senyawa epoksi. Kandungan bilangan oksiran sangat dipengaruhi oleh suhu, hal tersebut dikarenakan suhu akan meningkatkan pengikatan oksigen pada ikatan 
rangkap [7]. Dari hasil penelitian yang dilakukan dengan menggunakan asam sulfat $1,5 \%$ diperoleh bilangan oksigen oksiran maksimum sebesar 1,872 dengan bilangan iodium sebesar $0,96 \mathrm{~g}$ $\mathrm{I}_{2} / 100 \mathrm{~g}$ dengan waktu reaksi selama 300 menit. Hubungan ini digambarkan dengan grafik bar pada Gambar 6 yang menunjukkan, semakin tinggi persen tingkat epoksidasi maka bilangan iod akan semakin menurun.

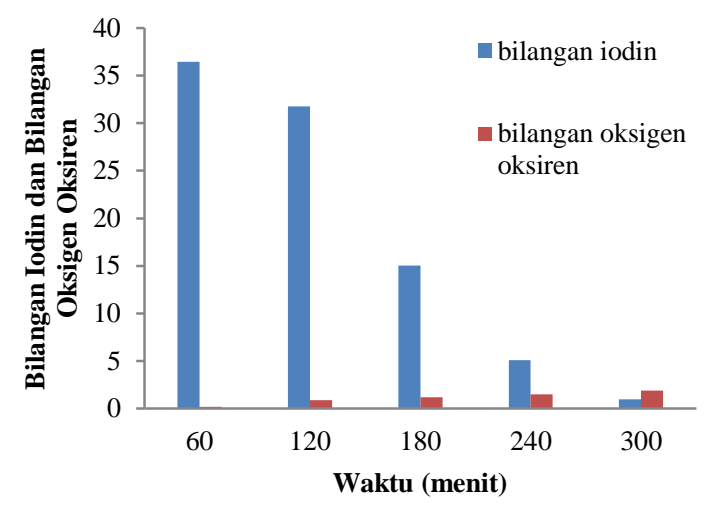

Gambar 6. Hubungan antara Bilangan Iodin dan Bilangan Oksigen Oksiren

\section{Kesimpulan}

Reaksi epoksidasi merupakan reaksi pembentukan gugus oksiran dengan cara oksidasi ikatan rangkap yang terdapat dalam minyak goreng bekas dengan menggunakan peroksi asam asetat glasial dan $\mathrm{H}_{2} \mathrm{SO}_{4}$ sebagai katalisator. Berdasarkan hasil penelitian menunjukkan bahwa kandungan oksigen oksiren yang paling baik adalah 1,872 , bilangan iod $0,96 \mathrm{~g} \mathrm{I}_{2} / 100 \mathrm{~g}$ dengan konversi $62,259 \%$ pada kondisi reaksi $60^{\circ} \mathrm{C}$, waktu reaksi 300 menit dan konsentrasi katalis $\mathrm{H}_{2} \mathrm{SO}_{4} 1,5 \%$.

\section{Daftar Pustaka}

[1] B. Qi, L. Lou, K. Yu, W. Bian, dan S. Liu, Selective Epoxidation of Alkenes with $\mathrm{H}_{2} \mathrm{O}_{2}$ Over Efficient and Recyclable Manganese Oxides, Catalysis Communication 15, (2011), 52-55.

[2] D. Derawi, J. Salimon, dan W. A. Ahmed, Preparation of Epoxidised Palm Olein as Renewable Material by using Peroxy Acids, The Malaysian Journal of Analytical Science, 18 (3), 2014, 584-591.

[3] M. D. Serio, R. Turco, P. Pernice, A. Aronne, F. Sannino, dan E. Santacesaria, Valuation of $\mathrm{Nb}_{2} \mathrm{O}_{5}-\mathrm{SiO}_{2}$ Catalysts in Soybean Oil Epoxidation. Catalysis Today. Vol 192, (2012), 112-116.

[4] M. S. Sinaga, Optimasi Proses Pembuatan Senyawa Epoksi dari Metil Ester Palm Fatty
Acid Distillate, Tesis, Universitas Sumatera Utara, Medan, 2005.

[5] M. S. Sinaga, Pengaruh Katalis $\mathrm{H}_{2} \mathrm{SO}_{4}$ pada Reaksi Epoksidasi Metil Ester PFAD (Palm Fatty Acid Distillate), Jurnal Teknologi Proses, ISSN 1412-7814, (2007), 70-74.

[6] N. Riyanti, Minyak Epoksi dari CPO Sebagai Processing Aid pada Pembutan Barang Jadi Karet Nitril-Butadien-PVC, Skripsi, Institut Pertanian Bogor, Bogor, 1992.

[7] R. Alamsyah, Pembuatan Senyawa Epoksi Minyak Sawit Mentah (CPO) pada Tingkat Konsentrasi Pelarut dan Waktu Reaksi Berbeda, Jurnal Hasil Penelitian Industri. Vol 26, No.1. ISSN: 2089-5380, (2013), 1927.

[8] R. Allundaru, dan T. W. Sitio, Studi Kinetika Reaksi Epoksidasi Minyak Sawit, Skripsi, Universitas Diponegoro, Semarang, 2013.

[9] R. Ariatmi, D. Mangunwidjaja, A. Suryani, Machfud, dan Sudradjat, Optimasi Proses dan Kinetika Reaksi Epoksidasi Minyak Jarak Pagar (Jatropha curcas L.) dengan Hidrogen Peroksida, Jurnal Teknologi Industri Pertanian, Vol 18 (2), (2010), 66-70.

[10] R. J. Gall, dan F. P. Greenspan, Epoxy Compound From Unsaturated Fatty Acid Ester, Industrial and Engineering Chemistry 47 (1), (1955), 147-148.

[11] R. Mungroo, V.V. Goud, N. C. Pradhan, dan A. K. Dalai, Modification of Epoxidased Canola Oil, Asia Pasific Journal of Chemical Engineering, 6, (2011), 14-22.

[12] S. Nasution, Pembuatan Senyawa Epoksi dari Metil Ester Asam Lemak Sawit Destilat Menggunakan Katalis Amberlite, Tesis, Universitas Sumatera Utara, Medan, 2009.

[13] S. P. Kayun, Kajian Strategi Pengembangan Industri Biodiesel Berbasis Minyak Jelantah di Indonesia, Tesis, Institut Pertanian Bogor, Bogor, 2007.

[14] T. F. Adepoju dan O. Olawale, AcidCatalyzed Esterification of Waste Cooking Oil with High FFA for Biodiesel Production, Chemical and Process Engineering Research, ISSN 22247467 (Paper) ISSN 2225-0913 (Online), Vol.21, (2014), 80-85.

[15] T. Saurabh, M. Patnaik, S. L. Bhagt, dan V. C. Renge, Epoxidation of Vegetable Oils: a Review, International Journal of Advanced Engineering Technology, E-ISSN 09763945, 2011.

[16] V. V. Goud, N. C. Pradhan, dan A. V. Patwardhan, Epoxidation of Karanja (Pongamia glabra) Oil by $\mathrm{H}_{2} \mathrm{O}_{2}$, JAOCS. Vol 83, No 7, (2006 ), 635-640. 
Jurnal Teknik Kimia USU, Vol. 6, No. 3 (September 2017) 